\title{
O brincar, o brinquedo e a brinquedoteca: Um balanço acerca da presença/ausência da concepção infância/criança na produção acadêmica
}

\author{
Tatiani Rabelo Lapa Santo* \\ Claudia Panizzolo**
}

\begin{abstract}
Resumo
Este trabalho, ao tratar da pesquisa com crianças, procura definir a concepção de infância e de criança e situá-las historicamente a partir das conquistas advindas da legislação e da produção acadêmica, visando compreender a produção de cultura pelas crianças e a importância de teorias e metodologias que possibilitem sua investigação a partir da Imprensa Periódica Educacional. Para tal, foram selecionadas três revistas: Cadernos de Pesquisa, Educação \& Sociedade e Perspectiva e realizado um levantamento seguido de revisão bibliográfica com os artigos publicados entre 1991 e 2009. Os resultados da investigação apontam para a valorização das crianças, vistas como sujeitos de direitos. Em todos os trabalhos analisados constata-se a ênfase dada pelos autores da necessidade de considerar a criança como um ser capaz de falar em seu próprio direito.
\end{abstract}

Palavras-chave: Criança; Infância; Imprensa Periódica.

\section{Playing, toy and toy library: considerations about the presence / absence of childhood / child conception in} academic prodution

\begin{abstract}
This work aims to define the conception of childhood and children by analyzing repports related to researches with children, and place them historically according to the conquests of the legislation and the academic production. It also targets to understand children's culture production and the importance of theories and methodologies that can make their investigation possible through Educational Periodical Press. In order to do so three journals were selected: Cadernos de Pesquisa, Educação e Sociedade and Perspectiva. It was performed a bibliographic review with the articles published between 1991 and 2009, giving priority to papers related to childhood, children and their culture. The research results point to the valorization of children, seen as subjects of rights. In all studies analyzed it is clear the emphasis given by the authors for the need to consider the child as able to speak in their own right.

Key words: child; Childhood; Periodical Press.
\end{abstract}

\section{Introdução}

O presente artigo é fruto do Projeto denominado "Estudos sobre o brincar o brinquedo e a brinquedoteca: a presença/ausência da cultura lúdica infantil na produção acadêmica", financiado pela FAPEMIG (Fundação de Amparo à Pesquisa do Estado de Minas Gerais), concluída no primeiro semestre de 2011 na Universidade Federal de Alfenas-MG.

Este estudo investigou a partir da revisão bibliográfica a produção sobre a cultura lúdica infantil nos aportes da Sociologia da Infância: o modo como as pesquisas compreendem, observam e analisam as diversas formas de ser criança; e como se constituem, nas atuais pesquisas, os objetos de estudos, os referenciais teóricos, conceitos e categorias relacionadas ao brincar, brinquedo, brinquedoteca.

Nesse sentido, procurou responder aos

* Endereço eletrônico: tatianirabelo@ hotmail.com

** Endereço eletrônico: claudiapanizolo@uol.com.br seguintes questionamentos: Qual lugar a infância e a criança ocupam nas produções acadêmicas? Quem são os sujeitos que provocam, discutem e polemizam questões relativas à cultura infantil e cultura lúdica? Como a produção acadêmica propõe a produção de uma cultura infantil lúdica no espaço da brinquedoteca? Como as pesquisas apresentam o foco de suas análises na produção da cultura infantil pelas crianças enquanto brincam? Quais as metodologias, procedimentos e instrumentos que se tem construído e utilizado nas pesquisas?

A partir desses problemas, pautou-se nos seguintes objetivos específicos: investigar a produção da brincadeira e o jogo na brinquedoteca a partir do referencial da Sociologia da Infância; identificar concepções de brincar presentes nos textos que partem do reconhecimento das manifestações e expressões culturais das crianças; compreender o modo como as pesquisas apresentam o foco de suas análises na produção da cultura 
infantil pelas crianças enquanto brincam; contribuir para uma revisão bibliográfica ampla e minuciosa que contemple a pesquisa em Sociologia da Infância no que se refere à cultura lúdica.

\section{Uma breve análise sobre pesquisas nos periódicos}

As pesquisas com crianças têm aumentado nas últimas décadas. Pode-se constatar que a criança tem ganhado um lugar diferenciado nos estudos sobre a infância. Educadores e pesquisadores da área da Educação Infantil procuram compreender cada vez mais as temáticas de estudos que tangem a faixa etária de 0 a 5 anos, trabalhando com práticas de pesquisa que a tratam como sujeito, possibilitando conhecer a infância nas várias formas de ser criança. $O$ crescente interesse tem levado pesquisadores e educadores a buscar teóricos que tratam a criança como um ser cultural, social e histórico, como apontam Alderson (2005), Montandon (2005), Muller (2005), Corsaro (2005), Sarmento (2005), Bouvier (2005) e Sirota (2005).

Nesse sentido, foram eleitos três periódicos nacionais: Cadernos de Pesquisa, Educação $e$ Sociedade e Perspectiva que apresentam suas pesquisas voltadas para área da educação, com intuito de analisar a produção voltada às pesquisas sobre/com criança e infância.

A Revista Cadernos de Pesquisa é uma publicação da Fundação Carlos Chagas, que tem como objetivo divulgar a produção acadêmica sobre educação, gênero e raça, com a finalidade de propiciar o debate acerca das principias questões e temas emergentes da área, com ênfase em publicações nacionais.

A Revista Educação \& Sociedade é uma publicação do Centro de Estudos em Educação e Sociedade da Universidade de Campinas (UNICAMP - SP) que se destina ao incentivo à pesquisa acadêmica e ao amplo debate sobre o ensino, em seus diversos aspectos.

Perspectiva é uma Revista do Centro de Ciências da Educação da Universidade Federal de Santa Catarina (UFSC) destinada à publicação de trabalhos inéditos sobre temas atuais e relevantes no âmbito da Educação, resultantes de estudos teóricos, pesquisas e discussões.

Essas revistas apresentam-se como instrumentos indispensáveis para atualização e aprimoramento de educadores e pesquisadores que trabalham na área da educação, mostrando uma gama de variedade temática em suas diversas sessões. Os periódicos são constituídos por artigos de pesquisadores brasileiros, além de traduções de renomados pesquisadores estrangeiros cuja temática vem a somar com o campo educacional.

Associada à escolha das revistas também foi definido o período temporal da investigação: 1991 a 2009. A definição do período está diretamente relacionada ao incremento dos estudos da Sociologia da Infância, na publicação do conjunto de relatórios sobre a situação da infância, no âmbito do Projeto Infância como um fenômeno social, coordenado por Jans Qvortrup em 1991, um expressivo impacto, na sequência provocando um significativo interesse acadêmico, expresso na criação de revistas científicas, publicação de artigos, incremento de eventos científicos e projetos de investigação.

A partir da definição dos periódicos e do período, a pesquisa voltou-se para a investigação acerca de como a produção acadêmica tem se pronunciado sobre o brincar, o brinquedo e a brinquedoteca, temáticas essas que atravessam o campo da infância, especialmente da Sociologia da Infância.

Em relação à metodologia utilizada para o desenvolvimento da pesquisa, foi feito um levantamento bibliográfico em que foram selecionados aproximadamente 157 artigos que tratam diversas temáticas, entre os artigos selecionados, 91 tratam o objeto de estudo criança/ infância e brincar/brinquedo/brinquedoteca.

Com a finalidade de tratar os dados coletados foi criado um banco de dados constituído pelos itens: título da pesquisa; autores; ano de publicação; assuntos; tipo de pesquisa; referencial teórico; formas de metodologias; procedimentos e instrumentos de pesquisa.

Esse banco de dados possibilitou chegar aos textos escolhidos para serem analisados no presente trabalho. Após a leitura na íntegra dos 91 artigos, foram elaborados tabelas e gráficos que apontam para os resultados desta pesquisa.

A primeira tabela e gráfico mostram o número de trabalhos encontrados nos periódicos citados acima entre 1991-2009.

\section{Tabela 1: total de artigos encontrados nos anos selecionados para pesquisa (1991-2009)}



infância/criança na produção acadêmica

\begin{tabular}{|c|c|c|c|c|c|c|}
\hline Ano & $\begin{array}{c}\text { Cadernos de } \\
\text { Pesquisa } \\
\text { (total em } \\
\text { números) }\end{array}$ & $\begin{array}{c}\text { Cadernos de } \\
\text { Pesquisa } \\
\text { (total \%) }\end{array}$ & $\begin{array}{c}\text { Educação e } \\
\text { sociedade } \\
\text { (total em } \\
\text { números) }\end{array}$ & $\begin{array}{c}\text { Educação e } \\
\text { sociedade } \\
\text { (total \%) }\end{array}$ & $\begin{array}{c}\text { Perspectiva } \\
\text { (total em } \\
\text { números) }\end{array}$ & $\begin{array}{c}\text { Perspectiva } \\
\text { (total \%) }\end{array}$ \\
\hline 1991 & 1 & 0,29 & 0 & 0 & 1 & 0,26 \\
\hline 1992 & 2 & 0,58 & 0 & 0 & 1 & 0,26 \\
\hline 1993 & 1 & 0,29 & 0 & 0 & 0 & 0 \\
\hline 1994 & 0 & 0 & 0 & 0 & 6 & 1,56 \\
\hline 1995 & 3 & 0,87 & 0 & 0 & 0 & 0 \\
\hline 1996 & 3 & 0,87 & 2 & 0,72 & 0 & 0 \\
\hline 1997 & 0 & 0 & 2 & 0,72 & 3 & 0,78 \\
\hline 1998 & 1 & 0,29 & 1 & 0,36 & 0 & 0 \\
\hline 1999 & 1 & 0,29 & 2 & 0,72 & 2 & 0,52 \\
\hline 2000 & 2 & 0,58 & 0 & 0 & 0 & 0 \\
\hline 2001 & 4 & 1,16 & 2 & 0,72 & 0 & 0 \\
\hline 2002 & 5 & 1,45 & 3 & 1,08 & 1 & 0,26 \\
\hline 2003 & 1 & 0,29 & 1 & 0,36 & 0 & 0 \\
\hline 2004 & 0 & 0 & 5 & 1,8 & 1 & 0,26 \\
\hline 2005 & 2 & 0,58 & 10 & 3,6 & 5 & 1,3 \\
\hline 2006 & 5 & 1,45 & 3 & 1,08 & 1 & 0,26 \\
\hline 2007 & 0 & 0 & 2 & 0,72 & 5 & 1,3 \\
\hline 2008 & 0 & 0 & 2 & 0,72 & 0 & 0 \\
\hline 2009 & 1 & 0,29 & 1 & 0,36 & 0 & 0 \\
\hline $\begin{array}{c}\text { Total de artigos } \\
\text { encontrados na } \\
\text { investigação em } \\
\text { cada periódico. }\end{array}$ & 29 & $100 \%$ & 36 & $100 \%$ & 26 & $100 \%$ \\
\hline
\end{tabular}

Fonte: Periódicos consultados para pesquisa.

Gráfico 1: Total de publicações por ano no periódico Cadernos de Pesquisa, Educação e Sociedade e Perspectiva:

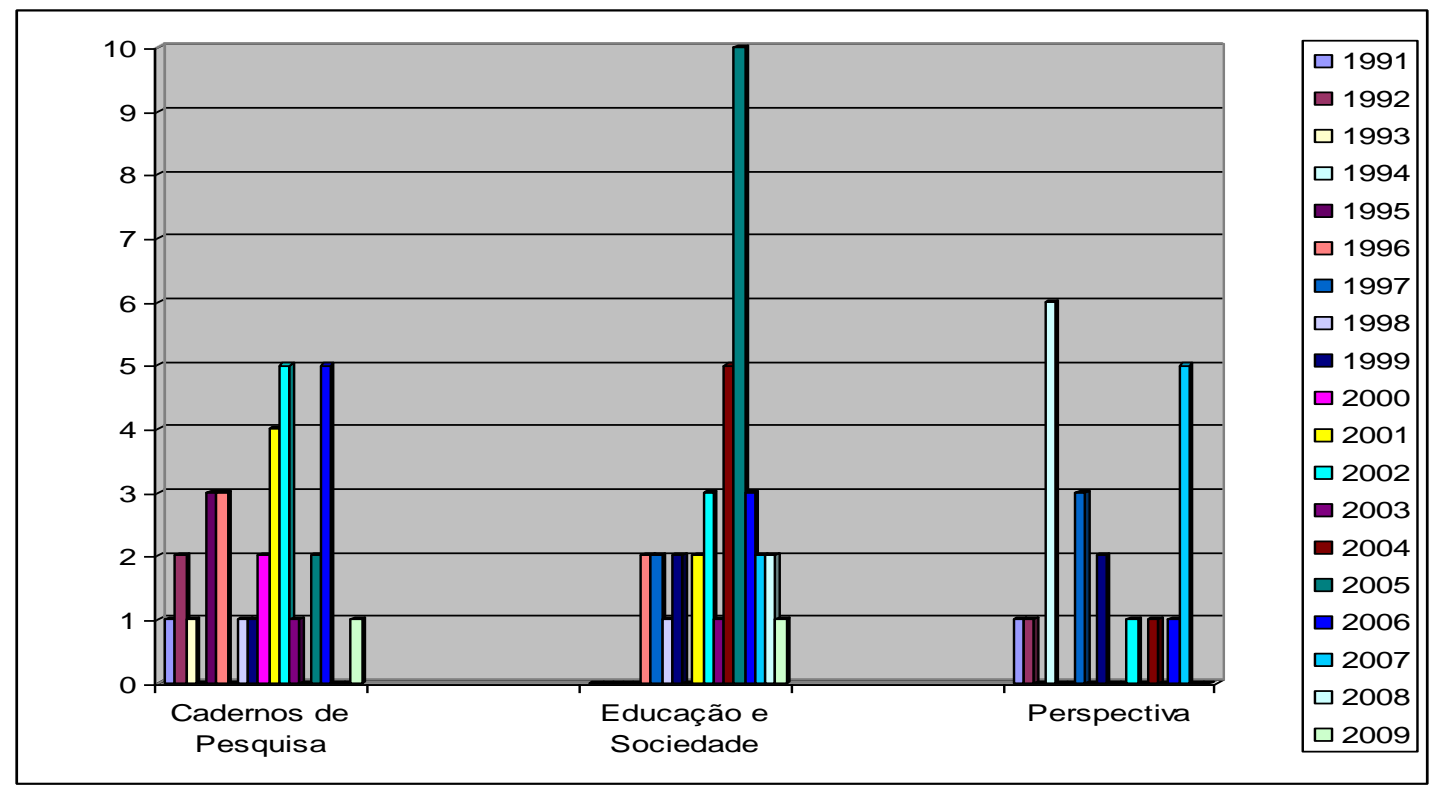


Constata-se, a Revista Educação $e$ Sociedade destacou-se dentre os três periódicos como aquela que concentra o maior número de publicações nesses 18 anos pesquisados. O periódico publicou no período de 1991- 2009 trinta e seis artigos que tratam a temática de estudo de nossa pesquisa. Em relação aos anos de publicação, o ano de 2005 foi o que apresentou mais publicações, totalizando dez artigos escritos. Esse elevado número de publicações está relacionado, provavelmente, aos avanços alcançados a partir do ano de 1988, que foi o marco na produção teórica da Educação Infantil, devido à promulgação da Constituição Federal, mas sobretudo ao conjunto de relatórios publicados em 2001 sobre a situação da infância no âmbito do Projeto Infância como um fenômeno social, coordenado por Jans Qvortrup, proporcionando um crescimento acentuado, motivado pelo reconhecimento da importância de aprofundar os estudos da área e também devido à frequência com que os autores que pesquisam a temática citada anteriormente escreveram para o periódico. Nos outros anos as publicações tangiam a temas educacionais de forma geral. Entre os pesquisadores que publicaram neste ano, estão: Alderson (2005), Montandon (2005), Muller (2005), Corsaro (2005), Sarmento (2005), Bouvier (2005), Sirota (2005). Em seguida, os anos que apresentaram mais artigos publicados são os de 2002 e 2006, com a publicação de três artigos em cada ano. Este periódico é o único entre os três selecionados que apresenta cinco anos consecutivos sem publicações 1991-1995 (ver tabela 1).

A Revista Cadernos de Pesquisa apresenta 29 artigos publicados no período selecionado. Dos trabalhos encontrados nesses dezoito anos pesquisados, os anos de 2002 e 2006 foram os que apresentaram maior número de publicações, sendo igualmente escrito cinco artigos em cada ano. $\mathrm{O}$ fato do ano de 2002 ser o que contém mais publicações, provavelmente se deve, bem como na revista Educação e Sociedade, a expansão e crescimento acentuado do interesse pelo universo infantil, sendo impulsionado pelo marco da Constituição de 1988 e pelos incrementos e estudos sociológicos realizados por estudiosos na área da educação infantil. $\mathrm{O}$ ano de 2001 também se destacou como um dos que apresentaram maior número de publicações, com 4 artigos escritos por pesquisadores que provocam, discutem e polemizam questões relativas à cultura infantil e cultura lúdica, entre estes estão: Sirota (2001), Montandon (2001), Arce (2001).

A Revista Perspectiva é o periódico que menos apresentou publicações no período de 19912009, apresentando apenas 26 artigos. Entre as publicações realizadas neste periódico, o ano de 1994 se destacou pelo número de artigos publicados relacionados à temática da pesquisa (seis artigos). Nos anos de 2005 e 2007 foram publicados igualmente cinco artigos. Dos dezoito anos selecionados para pesquisa, este periódico apresentou nove anos sem publicar sobre a temática de estudo desta pesquisa.

Ao buscar nos periódicos quais as possibilidades de viver a infância atualmente, podese dizer que a crianças têm ganhado cada vez mais lugar nas produções acadêmicas e os pesquisadores e educadores que trabalham com o universo infantil têm se dedicado a compreender esta faixa etária, realizando pesquisas em que o sujeito de estudo é a própria criança, possibilitando conhecer as várias formas de viver a infância. Entre esses autores estão: Quinteiro (2000); Delgado \& Müller (2005); Sirota (2001), Montandon (2001), Sarmento (2004), Corsaro (2005), dentre outros.

Em relação à produção nacional pode-se constatar que esta tem crescido consideravelmente, de acordo com Müller e Delgado (2005) existe um campo desenvolvido e legítimo de pesquisas em educação da infância e de temáticas relacionadas ao brincar. Neste sentido, Quinteiro (2000); Delgado \& Müller (2005) também vêm intensificando as reflexões teórico-metodológicas sobre Educação e Sociologia da Infância. Dentre os autores brasileiros desta área, os mais proeminentes são: Ribeiro (2009); Quinteiro (2000, 2002a, 2002b); Cerisara (1992).

No entanto, a produção estrangeira é a que tem impactado há mais tempo, pois os estudos na área da Sociologia da Infância no Brasil são recentes e a produção estrangeira já era vista desde a década de 1960, quando o historiador Ariès (1960) falava da infância como uma construção social, dependente ao mesmo tempo do contexto social e do discurso intelectual, como é visto na sua obra "A criança e a vida familiar no Antigo Regime" publicado em 1960".

Um dos exemplos de publicação de artigos estrangeiros pode ser visualizado nos anos de 1998 e 1999 pela Revista Educação e Sociedade. Entre esses artigos estão os textos de Régine Sirota (2001) e Cléopâtre Montandon (2001) que se constituem, sem dúvida, como referenciais de pesquisa, sobretudo pela forma como as autoras apresentam seu texto, fazendo uma retrospectiva a partir das publicações sobre a infância na área da Sociologia 
da Infância enfatizando as produções de línguas francesa e inglesa, respectivamente.

No que se refere aos autores que escreveram para a revista no período de 1991-2009, podemos encontrar autores nacionais e estrangeiros, como mostram a tabela e o gráfico abaixo:

Tabela 2- Relação dos autores nacionais e estrangeiros que publicaram nos periódicos Cadernos de Pesquisa, Educação e Sociedade e Perspectiva no período de 1991-2009:

\begin{tabular}{|l|c|c|l|c|c|c|}
\hline Artigos & $\begin{array}{l}\text { Cadernos de } \\
\text { Pesquisa } \\
\text { (total em } \\
\text { números) }\end{array}$ & $\begin{array}{c}\text { Cadernos de } \\
\text { Pesquisa } \\
\text { (total \%) }\end{array}$ & $\begin{array}{l}\text { Educação e } \\
\text { Sociedade } \\
\text { (Total em } \\
\text { números) }\end{array}$ & $\begin{array}{c}\text { Educação e } \\
\text { Sociedade } \\
\text { (total \%) }\end{array}$ & $\begin{array}{l}\text { Perspectiva } \\
\text { (total em } \\
\text { números) }\end{array}$ & $\begin{array}{c}\text { Perspectiva } \\
\text { (total \%) }\end{array}$ \\
\hline $\begin{array}{l}\text { Publicação } \\
\text { brasileira }\end{array}$ & 24 & 6.96 & 22 & 7.92 & 20 & 5.20 \\
\hline $\begin{array}{l}\text { Publicação } \\
\text { estrangeira }\end{array}$ & 5 & 1.45 & 11 & 3.96 & 5 & 1.30 \\
\hline $\begin{array}{l}\text { Nipo- brasileira } \\
\text { Total de artigos } \\
\text { encontrados na } \\
\text { investigação em } \\
\text { cada periódico. }\end{array}$ & 0 & $100 \%$ & 36 & $100 \%$ & 26 & $100,00 \%$ \\
\hline
\end{tabular}

Fonte: Periódicos consultados para pesquisa

Gráfico 2: Relação dos autores nacionais e estrangeiros que publicou nos periódicos Cadernos de Pesquisa, Educação e Sociedade e Perspectiva no período de 1991-2009:

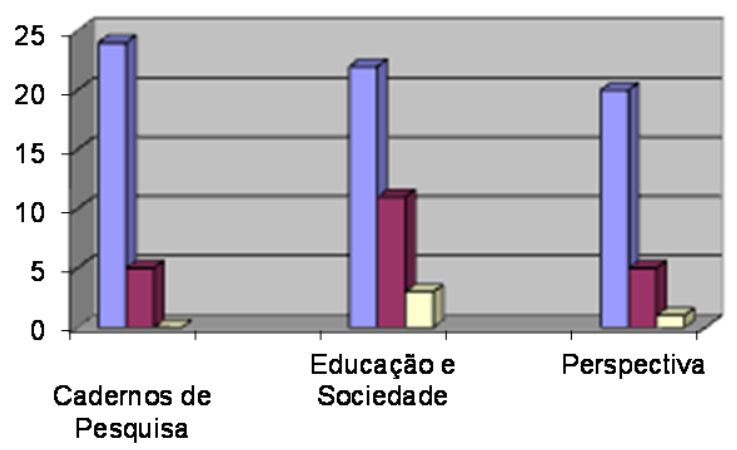

A tabela e o gráfico 2 permitem visualizar que o periódico Cadernos de Pesquisa publicou 24 artigos de autores brasileiros e 5 de estrangeiros. A Revista Educação e Sociedade divulgou 22 artigos escrito por autores brasileiros, 11 por estrangeiros e 3 pela escritora nipo-brasileira Tizuko Morchida Kishimoto (1997), que escreveu os artigos: "Brinquedo e brincadeira na educação na Educação Infantil japonesa: Proposta Curricular anos 90" no periódico Educação e Sociedade, vol.18 no.60 Campinas Dec. 1997; "Brinquedo, gênero e educação na brinquedoteca" (2008) e "O primeiro jardim de infância público do estado de São Paulo e a pedagogia frobeliana" (1996). Em seus textos a autora valoriza o brincar e a brincadeira, usando como referencial teórico autores que enfatizam os brinquedos e as brincadeiras como importantes espaços para a construção e formação na identidade das crianças. Dentre os autores que Kishimoto usa para embasamento teórico em seus trabalhos estão: Brougère (1995), Dias (2004), Almeida (1990), a autora é a única dentre todos que publicaram para os três periódicos a escrever sobre a temática brinquedoteca. Na revista Perspectiva aparecem 20 publicações de autores brasileiros, 5 de estrangeiros e um nipo-brasileiro.

Em relação aos pesquisadores que se dedicam aos estudos sobre crianças existem aqueles que buscam uma pesquisa "com" e "sobre" crianças e usam abordagens teórico-metodológicas e 
metodologias diversificadas como a revisão bibliográfica, pesquisa de campo com caráter qualitativo, observação participante, coleta de imagens e análise de entrevistas.

No que tange às diferentes abordagens teórico-metodológicas apresentadas nos periódicos, podemos verificar que autores com publicações nas revistas adotam como referencial teórico outros autores presentes nos periódicos, isto se constitui como um ciclo que se repete constantemente. Constatou-se que alguns autores escrevem a partir de um mesmo referencial, como Kishimoto (1997), que cita Brougère (2003) em todos os seus artigos durante o período da pesquisa.

No que diz respeito às abordagens teóricometodológicas presentes nos três periódicos selecionados para pesquisa, como demonstrado na tabela 3, há um número considerável de trabalhos referentes à Sociologia da Infância especificamente. Em escala menor aparecem as seguintes abordagens: a perspectiva dos autores italianos em alguns textos como o de Oliveira (2001) no trabalho "Manual de educação infantil de 0 a 3 anos", abordando as pedagogias italianas; Dias (2004) ao escrever sobre: "Qualidade na Educação Infantil da primeira infância: perspectivas pós-modernas"; Mello (2004) em "A educadora de creche: construindo suas identidades"; Corsaro (2005) em "Entrada no campo, aceitação e natureza da participação nos estudos etnográficos com crianças pequenas" totalizando 4 trabalhos dos 91 selecionados para pesquisa.

Nos três periódicos analisados, a perspectiva histórico-cultural, principalmente no que se refere ao pensamento de Vygotsky, foram encontrados 14 trabalhos e em proporção menor, verificamos a existência da perspectiva de Piaget em 7 trabalhos. É importante ressaltar a constatação de que alguns trabalhos fazem referência a mais de uma perspectiva teórico-metodológica, como por exemplo, no texto "O brincar na educação infantil" de Wajskop (1995) da Revista Cadernos de Pesquisa, n.2, p.62-69; outro intitulado como: "O primeiro jardim de infância público do estado de São Paulo e a pedagogia frobeliana", de Kishimoto (1997), escrito na Revista Cadernos de Pesquisa em 1997, dentre outros presentes nos periódicos analisados.

Os procedimentos metodológicos encontrados nos trabalhos presentes nas revistas foram diversos, dentre estes a pesquisa bibliográfica foi a mais usada nos artigos (ver tabela 3). Esse tipo de pesquisa é uma etapa fundamental em todo trabalho cientifico, pois exerce influência em todas as etapas da pesquisa. A pesquisa bibliográfica é constituída por levantamento, fichamento e construção de um arquivo que suporte os dados relacionados da pesquisa. Entre os autores que escrevem para as revistas pesquisadas e usam esta metodologia estão: Sarmento (2004), (2005), Kishimoto (1997), Sirota (2005), Montandon (2005), Alderson (2005) e outros. Estes pesquisadores realizam uma leitura e discussão mais sistemática dos autores e proporcionam aos leitores uma compreensão do tema estudado.

A pesquisa de campo foi segunda metodologia mais utilizada pelos pesquisadores (ver tabela 3), que é realizada através de observação dos fatos in loco, realizando coleta de dados, análise e interpretação, com o objetivo de compreender o tema da pesquisa. Entre os pesquisadores que realizaram pesquisa de campo nos periódicos analisados estão: Kishimoto (1997), Muller (2005), Rocha (1997-1999), Goulart (1999), Mello (2004), Belloni (2004), Montandon (2005), Corsaro (2005), Sirota (2005), dentre outros.

Posteriormente encontrou-se o uso do registro etnográfico, que aparece como uma forte tendência para realização de pesquisas com crianças; este registro pode estar sendo usado constantemente em pesquisa, pois, segundo Sarmento (2003), a etnografia procura ver a vida, tal como ela é cotidianamente conduzida, simbolizada e interpretada pelos atores sociais.

A metodologia menos utilizada nos periódicos analisados foi a iconografia, que é encontrada apenas uma vez no periódico Educação e Sociedade no vol. 25, n. 86, p. 57-74, abril 2004, no artigo "Imagens de crianças e crianças nas imagens: Representações da infância na iconografia pedagógica nos séculos XVII e XVIII", escrito por Loic Chalmel (1996). A iconografia é uma forma de linguagem visual que usa imagens para mostrar o tema estudado, esta metodologia estuda a origem da formação das imagens.

Constatamos nas metodologias utilizadas a presença de cinco procedimentos diferentes, entre esses os registros fotográficos, bastante vistos nas pesquisas, pois abordam diversos ângulos de um mesmo objeto de pesquisa, tornando-se um constante convite à releitura.

Outro procedimento utilizado são as filmagens em vídeo. Esse recurso ajuda a capturar imagens que mostram as várias formas de ser criança, pois possibilita ver com maior expansão e expressão, o que não é visto em um primeiro 
contato.

A observação participante também tem sido utilizada nas pesquisas com crianças, pois esta é sustentável, comprometida e requer que o pesquisador não apenas observe repetidamente, mas também participe como um membro do grupo.

Nos periódicos aparecem questionários e entrevistas estruturadas e semi-estruturadas, como pode ser visto nos trabalhos de: Corsaro (2005), Kishimoto (1997), Muller (2005), Quinteiro (2000, 2002a, 2002b); Cerisara (1992).

Em relação aos procedimentos utilizados a tabela e gráfico abaixo apresentam os seguintes resultados:

Tabela 3- Total de procedimentos metodológicos encontrados nos periódicos analisados no período 19912009:

\begin{tabular}{|c|c|c|c|c|c|c|}
\hline $\begin{array}{l}\text { Procedimentos } \\
\text { Metodológicos }\end{array}$ & $\begin{array}{l}\text { Cadernos de } \\
\text { Pesquisa } \\
\text { (total em } \\
\text { números) }\end{array}$ & $\begin{array}{l}\text { Cadernos de } \\
\text { Pesquisa } \\
\text { (total \%) }\end{array}$ & $\begin{array}{l}\text { Educação e } \\
\text { Sociedade } \\
\text { (total em } \\
\text { números) }\end{array}$ & $\begin{array}{c}\text { Educação e } \\
\text { Sociedade } \\
\text { (total \%) }\end{array}$ & $\begin{array}{l}\text { Perspectiva } \\
\text { (total em } \\
\text { números) }\end{array}$ & $\begin{array}{c}\text { Perspectiva } \\
\text { (total \%) }\end{array}$ \\
\hline Bibliográfico & 16 & 4.64 & 19 & 6.84 & 18 & 4.68 \\
\hline Empírico & 1 & 0.29 & 1 & 0.36 & 0 & \\
\hline Etnográfico & 0 & & 6 & 2.16 & 0 & \\
\hline Iconografia & 0 & & 1 & 0.36 & 0 & \\
\hline Pesquisa de campo & 9 & 2.61 & 4 & 1.44 & 6 & 1.56 \\
\hline $\begin{array}{l}\text { Outros (resenhas, } \\
\text { dossiês) }\end{array}$ & 3 & 0.87 & 5 & 1.80 & 2 & 0.52 \\
\hline $\begin{array}{l}\text { total de artigos } \\
\text { encontrados na } \\
\text { investigação em } \\
\text { cada periódico. }\end{array}$ & 29 & $100 \%$ & 36 & $100 \%$ & 26 & $100 \%$ \\
\hline
\end{tabular}

Fonte: Periódicos consultados para pesquisa

Gráfico 3- Total de procedimentos metodológicos encontrados nos periódicos Cadernos de Pesquisa, Educação e Sociedade e Perspectiva:

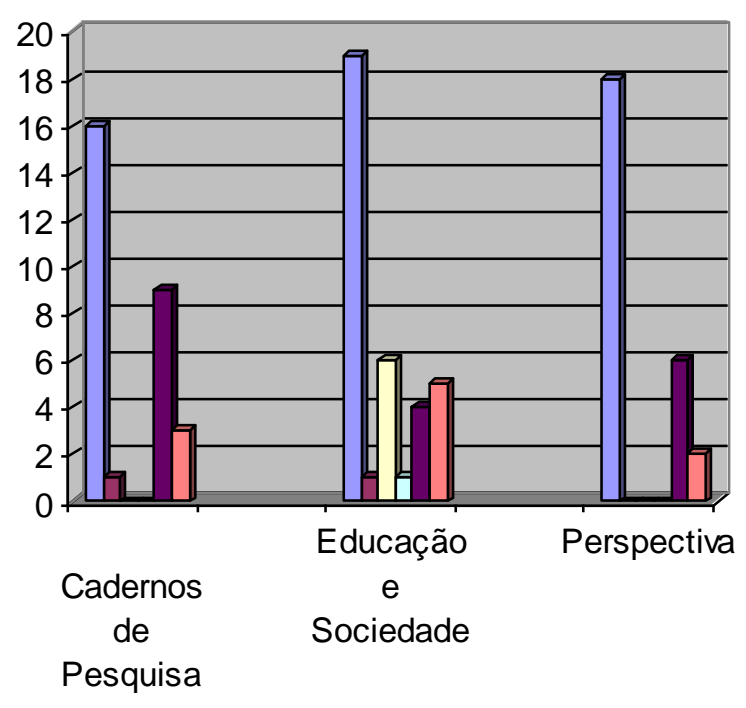

\begin{tabular}{|l|}
$\square$ Pesquisa Bibliografica \\
$\square$ Pesquisa Empirica \\
$\square$ Pesquisa Etnografica \\
$\square$ Pesquisa Iconografica \\
$\square$ Pesquisa de Campo \\
$\square$ Outros ( resenhas, dossies) \\
\hline
\end{tabular}

Verifica-se na tabela e gráfico 3 a distribuição dos procedimentos metodológicos usados nos periódicos analisados. No último item o termo "outros" se refere aos diferentes textos que aparecem nos periódicos, como resenhas e dossiês que não fazem menção a metodologias de pesquisa. 


\section{A presença da temática brincar, brinquedo e brinquedoteca na Imprensa Periódica}

Com intuito de dar visibilidade à amostragem pesquisada das temáticas relacionadas ao brincar, brinquedo e brinquedoteca, entre os anos de 1991 a 2009, foi elaborado uma tabela e um gráfico (abaixo) para melhor compreensão das temáticas abordadas.

Tabela 4- Total de artigos encontrados sobre a temática brincar, brinquedo e brinquedoteca nos periódicos pesquisados.

\begin{tabular}{|c|c|c|c|c|c|c|}
\hline Artigos & $\begin{array}{c}\text { Cadernos de } \\
\text { Pesquisa }\end{array}$ & $\%$ & $\begin{array}{c}\text { Educação e } \\
\text { Sociedade }\end{array}$ & $\%$ & Perspectiva & $\%$ \\
\hline Brincar & 2 & 0.58 & 6 & 2.16 & 7 & 1.82 \\
\hline brinquedo & 2 & 0.58 & 6 & 2.16 & 7 & 1.82 \\
\hline brinquedoteca & 0 & & 1 & 0.36 & 0 & $100 \%$ \\
\hline Total & 29 & $100 \%$ & 36 & $100 \%$ & 26 & \\
\hline
\end{tabular}

Fonte: Periódicos consultados para pesquisa

Gráfico 4- Total de artigos encontrados sobre a temática brincar, brinquedo e brinquedoteca nos periódicos Cadernos de Pesquisa, Educação e Sociedade e Perspectiva:
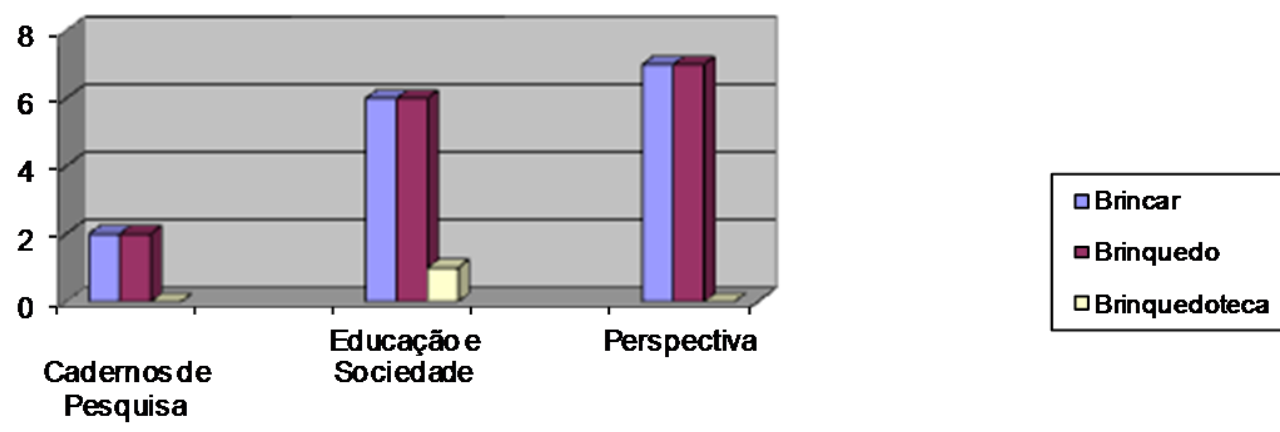

Dos 29 dos artigos publicados pela revista Perspectiva selecionados para análise foram encontrados 7 artigos que tratam da temática brincar, 7 que tratam da brincadeira e nenhum relacionado à brinquedoteca. Um dos motivos desses resultados é o fato de que essas temáticas foram por muito tempo temas de estudo principalmente da Psicologia. Constata-se assim que são os autores da área da Psicologia que têm se dedicado ao estudo sobre o brinquedo, direcionando suas produções sobretudo na perspectiva do uso do objeto sobre a criança, ou seja, a criança não era considerada como o sujeito e sim objeto de estudo. Os exemplos citados acima são vistos por exemplo no livro "Brinquedo e Cultura" de Guilles Brougère escrito no ano de 1995, utilizado como referencial teórico por Kishimoto (2008) no trabalho intitulado "Brinquedo, gênero e a educação na brinquedoteca" na Revista Educação e Sociedade.
A Revista Educação e Sociedade também tem um volume significativo de publicações. Vale ressaltar que foi o único periódico que publicou sobre o tema brinquedoteca. Essa revista apresenta 13 artigos escritos: contém um 1 referente à brinquedoteca, 6 que tratam do brincar e outros 6 que tratam da temática brinquedo.

A Cadernos de Pesquisa é a que menos publicou acerca do brincar, do brinquedo e da brinquedoteca. Dos 26 artigos selecionados para pesquisa foram encontrados 2 sobre a temática brincar, 2 relacionados à brincadeira e nenhum sobre brinquedoteca

Sobre os artigos que tratam o brincar, brinquedo e a brinquedoteca, é importante destacar que embora apareça uma pequena quantidade de artigos publicados, os autores que escrevem sobre essa temática trazem um olhar holístico ao apresentar os resultados de suas pesquisas 
considerando a criança como um ser social, cultural e indissociável, valorizando a criança como um ser capaz que possui autonomia no mundo do qual faz parte. Como mostra Oliveira, (2008) na Revista Perspectiva ao se referir ao brincar:

O brincar promove experiências sociais, as quais contribuem com o desenvolvimento cognitivo, seja indiretamente promovendo o crescimento da habilidade de se colocar no lugar do outro, seja diretamente fornecendo oportunidade das crianças perceberem como são os outros, (n. 22, p. 129-137).

$\mathrm{O}$ brincar e as brincadeiras aparecem nos textos como uma possibilidade de interagir com o mundo a sua volta oferecendo à criança a oportunidade de assimilar o seu mundo exterior ao interior sem precisar modificar a realidade externa, como apresenta Corsaro (2005) e Almeida (1990).

Autores como Kishimoto (2008), Wajskop (1995), Pedrosa (1995), Carvalho (2007), Oliveira (2008), Souza (2008) veem o brincar como uma atividade vital na vida da criança por mesclar realidade e fantasia, estimulando a criança a se socializar com outros sujeitos, como aparece no texto "O brincar e o desenvolvimento infantil" de Ana Maria Faraco de Oliveira", na Revista Perspectiva, n. 22, (1995, p. 129-137).

Nos periódicos analisados no período de 1991-2009, os autores convergem no sentido de que as crianças ao brincarem se divertem e entram em um mundo de fantasia, onde tudo se torna possível, em que criam, reproduzem e reiteram cada brincadeira, começando sempre uma nova brincadeira como aparece nos textos de Pedrosa (1993), Piacentini (2007), Volpato (2002), Corsaro (2005), Kishimoto (2008) e Kishimoto (1997).

Nos periódicos os pesquisadores consideram e valorizam o que a criança produz, encontraram-se trabalhos e pesquisas com crianças e não apenas sobre crianças. Dentre os textos que discutem a pesquisa com crianças está o de Kishimoto (2008), intitulado "Brinquedo, gênero e a educação na brinquedoteca" da revista Educação $e$ Sociedade, que discute o papel do brincar e do jogo dentro da brinquedoteca, temáticas importantes ao se realizar pesquisas com crianças. O brincar no texto da referida autora aparece como possibilidade de construção e reconstrução das brincadeiras entre as crianças, como um lugar que favorece a brincadeira livre. Nesta pesquisa, a autora define o conceito de brinquedo como o material que dá suporte à brincadeira; está o lúdico em ação, ou seja, o uso das regras do jogo que provêm do mundo social. Isso implica afirmar que ninguém nasce sabendo brincar, que o brincar pressupõe aprendizagem social.

A brinquedoteca também é vista nos textos analisados com um espaço que proporciona a brincadeira e o jogo por meio de atividades livres e voluntárias, em que as crianças expressam seus desejos, suas vontades, valendo-se de sua criatividade, elaborando suas próprias regras de convivência. Silva e outros (s/d) apontam que o espaço da brinquedoteca deve ser constituído da seguinte forma:

O espaço deve ter uma configuração visual e espacial que facilite o desenvolvimento da imaginação, espaços livres onde elas possam correr brincar, e construir casinhas, cabanas, lojas, castelos, espaço para roupeiro com espelhos e roupas, espaços para leitura, teatro, espaços para pintura e artes plásticas, espaços para jogos $e$ espaços com móveis com mesas, bancos, cadeiras de fácil manipulação para permitir a reorganização constante do local pelas crianças (p.3).

Portanto, constata-se em relação a produção acadêmica vista nos periódicos, a proposta de uma produção de cultura infantil lúdica no espaço da brinquedoteca, tratando esta como um espaço de construção e reconstrução do brincar.

\section{Conclusão}

O presente artigo procurou apresentar um recorte do trabalho concluído no primeiro semestre do ano de 2011, buscando através da leitura na íntegra dos 91 artigos apresentar como os pesquisadores abordam, escrevem e compreendem as temáticas relacionadas ao brincar, brincadeira e brinquedoteca.

Verificou-se nos trabalhos publicados nos três periódicos que, a partir de 1991 a produção acadêmica revela um novo olhar sobre a criança, despidos de ideias preconcebidas e procurando estudar a criança como um ser social, cultural e histórico, analisando o desenvolvimento infantil no contexto em que ele realmente acontece, como podemos verificar nos seguintes autores: Wajskop (1995), Macedo (1995), Carvalho (2007), Osteto (1991), Cerisara (1992), Pancera (1994), Oliveira 
(1994), Becchi (1994), Khisimoto (1994) e Souza (2008).

Em relação às temáticas brincar, brinquedo e brinquedoteca, constatou-se que embora se faça presente um pequeno número de publicações nos periódicos apresentados neste artigo, os autores que escrevem partem de um olhar em que o brincar é visto como algo capaz de fazer diferença na vida e no desenvolvimento, como algo processual que ajuda a socializar, aprender, desenvolver e acima de tudo leva a criança a se divertir, uma vez que proporciona alegria e prazer.

Constatou-se também que essas temáticas investigadas estão sendo atualmente mais valorizadas, pois, como apontam os textos selecionados para este artigo, o brincar/brinquedo/brinquedoteca proporcionam o faz-de-conta, a ludicidade e a construção e reconstrução de novas brincadeiras como podemos constatar no nosso dia-a-dia nas experiências vividas em contextos da Educação Infantil ao longo destes anos.

Enfim, é importante ressaltar que o exame e a investigação das produções teóricas foram riquíssimos, permitindo a reflexão sobre a infância e as temáticas relacionadas ao brincar, brinquedo e brinquedoteca vêm sendo tratadas atualmente por diversos pesquisadores da área, além de abrir possibilidades de futuras pesquisas em periódicos diferenciados. Durante a realização das pesquisas, os dados e as análises abriram discussões que possibilitaram acrescentar experiências e compreender melhor o que os periódicos Cadernos de Pesquisa, Educação \& Sociedade e Perspectiva trazem sobre criança e infância e temáticas relacionadas ao brincar, brinquedo e brinquedoteca.

\section{Referências Bibliográficas}

ALDERSON, P. As crianças como pesquisadoras: Os efeitos dos direitos de participação sobre a metodologia de pesquisa. Revista Educação e Sociedade, vol. 26 n.91. Campinas Maio/Agosto. 2005.

ALMEIDA, P. N. Educação lúdica técnicas e jogos pedagógicos. 8 ed. São Paulo: Loyola,1990.

ARCE, A. Documentação oficial e o mito da educadora nata na educação infantil. Revista
Cadernos de Pesquisa.n.113 São Paulo, julho, 2001.

ARIÈS, P. A Criança e a Vida Familiar no Antigo Regime. Lisboa: Relógio D'Água, 1988.

BECCHI, E. Retórica de infância. Revista Perspectiva, Florianópolis, n. 22, p. 63-95, agosto /dez. De 1994.

BELLONI, M. L; GOMES, N. G. Infância, mídias e aprendizagem: autodidaxia e colaboração. Revista Educação e Sociedade, Campinas, vol.29 no. 104. Campinas, outubro, 2008.

BOUVIER, S. M. Transformação dos modos de socialização das crianças: Uma abordagem sociológica. Revista Educação e Sociedade, Campinas, vol.26, n.91, p.391-403, maio/agosto, 2005.

BROUGÈRE, Gilles. Brinquedo e cultura. São Paulo: Cortez, 1995.

CAMPOS, Maria Malta. Por que é importante ouvir a criança? A participação das crianças pequenas na pesquisa científica. In: CRUZ, Silva Helena Vieira. (org.). A criança fala; a escuta de crianças em pesquisas. São Paulo: Cortez. 2008, p. 35-42.

CARVALHO. D; Quinteiro. J; SERRÃO, M. I. Infância, educação e escola. Revista Perspectiva, Florianópolis, vol. 25, n.1 - janeiro/junho, 2007.

CERISARA, A. B. Educação infantil: Um jogo de quebra- cabeça ou quebrando a cabeça? Revista Perspectiva, Florianópolis, vol.17, p.11-24, 1992.

CHALMEL, L. Imagens de crianças e crianças nas imagens: Representações da infância na iconografia pedagógica nos séculos XVII e XVIII. Revista Educação e Sociedade. no vol. 25, n. 86, p. 57-74, abril 2004.

CORSARO, A. W. Entrada no campo, aceitação e natureza da participação nos estudos etnográficos com crianças pequenas. Revista Educação e Sociedade, Campinas, vol. 26, n. 91, p.443-464, Maio/Ago. 2005.

DELGADO, A. C. Coll; MULLER, F. Em busca de metodologias investigativas com as crianças e suas culturas. Revista Cadernos de Pesquisa, vol.35, n.125 São Paulo Maio/Agosto. 2005. 
DIAS, S. L. Qualidade na educação da primeira infância: Revista Educação e Sociedade, vol. 26, n. 86, p. 74-84, abril 2004.

GOULART, A. A. M; QUINTEIRO, J. Infância: fios e desafios da pesquisa. Revista Educação e Sociedade, vol.18 n.60 Campinas, dezembro, 1996.

HADDAD, L. Políticas integradas de educação e cuidado infantil: desafios, armadilhas e possibilidades. Revista Cadernos de Pesquisa, v.36 n.129 São Paulo set./dez. 2006.

KISHIMOTO. M. T; ONO, A. T. Brinquedo, gênero e a educação na brinquedoteca. Revista Educação e Sociedade, Campinas, ProProsições v.19 n.3 Campinas set./dez. 2008.

Brinquedo e brincadeira na educação infantil japonesa: Proposta curricular anos 90. Revista Educação e Sociedade, vol.18 n.60 Campinas, dezembro, 1997.

O jogo e a educação infantil. Revista Perspectiva, Florianópolis, n. 22, p.105128, ano 12, agosto-dezembro, 1994.

MACEDO, de Lino. Os jogos e sua importância na escola. Revista Cadernos de Pesquisa, São Paulo, n.93, p.5-10, maio 1995.

MELLO, M. A. A educadora de creche: construindo suas identidades (Maria Aparecida Mello- Resenha. Revista Educação e Sociedade n. vol.25, n.86,p.255-259, abril/2004.

MONTANDON. C; LONGCHAP, P. Você disse autonomia? Uma breve percepção da experiência com crianças. Revista Perspectiva, Florianópolis, vol.25, n. 1, p. 105-126, janeiro/junho, 2007.

. As práticas educativas parentais e a experiência das crianças. Revista Educação e Sociedade. Vol. 26 no. 91. Campinas Maio/Agosto, 2005.

MULLER, F; COLL, A. C. Sociologia da infância: pesquisa com crianças. Revista Educação e Sociedade, vol.26 n.91 Campinas Maio/Agosto, 2005.

OLIVEIRA, A. M. F. O brincar e o desenvolvimento infantil. Revista Perspectiva,
Florianópolis, n. 2008.2, vol. 26, n.2 - jul-dez 2008.

OSTETO, L. E. Imagens da infância no Brasil escravocrata. Revista Perspectiva, Florianópolis, vol.9, n.16, p.133-169, jan/dez.1991.

PANCERA. C. Semânticas da infância. Revista Perspectiva, Florianópolis, ano 12, n. 22, p. $97-$ 104, ago./dez. 1994.

PEDROSA, M. I; CARVALHO, A. M. A interação social e a construção da brincadeira. Revista Cadernos de Pesquisa, São Paulo, 1995, p. 60-65.

PIACENTINI, A. A. A. criação do Museu do brinquedo da Ilha de Santa Catarina da Universidade Federal de Santa Catarina. Revista Perspectiva, Florianópolis, vol.25, n.2, p.595-610, julho/dezembro, 2007.

QUINTEIRO, J. Sobre a emergência de uma Sociologia da Infância: Contribuições para o debate. Revista Perspectiva, Florianópolis, v. 20, n. Especial, p. 137-162, jul./dez.2002.

RIBEIRO, C. de Sá; DELVAL, J. A construção da noção de direitos humanos em crianças e adolescentes. Revista Cadernos de Pesquisa, São Paulo,n.104,p.76-100, julho,1998.

RIBES. R. M; Gonçalves. R; RAQUIEL. S. Pesquisador e criança: Dialogismo e alteridade na produção da infância contemporânea. Revista Cadernos de Pesquisa, v.39, n.138, p.1019-1035, set/dez. 2009.

ROCHA, E. A. C. A pesquisa sobre educação infantil: trajetórias e perspectivas. Revista Perspectiva, Florianópolis, v17, n. Especial, p.6171, julho/dezembro, 1999.

Infância e pedagogia: dimensões de uma intricada relação. Revista Perspectiva, Florianópolis, n. 28, vol.15, p.21-33, julho/dezembro 1997.

SARMENTO, Manuel Jacinto. 2004. As culturas da infância nas encruzilhadas da Segunda Modernidade. Sarmento, M.J; CERISARA, A.B. Crianças e miúdos: perspectivas sociopedagógicas da infância e educação. Porto: Asa Editores.

Manuel Jacinto. 2005. Gerações e 
alteridade: interrogações a partir da sociologia da Infância. Revista Educação e Sociedade, Campinas, vol.26, n. 91, p.361-78, maio/ago.

J. Manuel. Crianças: Educação, cultura e cidadania activa. Refletindo e torno de uma proposta de trabalho. Revista Perspectiva, Florianópolis, v. 23, n. 01, p. 17-40, jan./jul. 2005.

SILVA, Sheila Helena Conceição da Silva e outros. s/d. Brinquedoteca: um espaço criativo; projeto do Centro de Educação. X Encontro de Extensão. UFPB-PRAC.

SIROTA, R. Emergência de uma sociologia da infância: evolução do objeto e do olhar. Revista Cadernos de Pesquisa, n.112 São Paulo mar. 2001.

Primeiros amigos: Os aniversários da infância, dar e receber. Revista Educação e
Sociedade, Campinas, vol. 26, número 91,2005. SOUZA. M. Brincando com a arte. Revista Perspectiva, Florianópolis, n. 2008.2, v. 26, n.2 jul-dez 2008.

VOLPATO, G. Brinquedo: Reflexões a partir da teoria critica. Revista Educação e Sociedade, vol.23 n. 81 Campinas Dezembro. 2002.

VOLPATO, G. Brinquedo: Reflexões a partir da teoria critica. Revista Educação e Sociedade, vol.23 n. 81 Campinas Dezembro. 2002.

WAJSKOP, G. O brincar na educação infantil. Revista Educação e Sociedade, Campinas, n.92, p.62.69, fevereiro. 1995.

WAJSKOP, G. O brincar na educação infantil. Revista Educação e Sociedade, Campinas, n.92, p.62.69, 1995.

\section{Sobre as autoras:}

Tatiani Rabelo Lapa Santo: Professora da Rede Municipal de Ensino do Município de Uberlândia-MG. Mestranda em Educação pela Faculdade de Educação na Universidade Federal de Uberlândia-MG.

Claudia Panizzolo: Professora Adjunta da Universidade Federal de São Paulo - UNIFESP. Coordenadora do Grupo de Pesquisa: Infância, Cultura e História - GEPICH, pesquisadora nas linhas História social e cultural da infância e da adolescência, e Infância e educação infantil: políticas, práticas e instituições.

Recebido em: 11/2013

Aprovado em: 07/2013 